\title{
BMJ Open Interventions to prevent aggression against doctors: a systematic review
}

\author{
Ann Raveel, ${ }^{1}$ Birgitte Schoenmakers ${ }^{1,2}$
}

To cite: Raveel A,

Schoenmakers B. Interventions to prevent aggression against doctors: a systematic review. BMJ Open 2019;9:e028465. doi:10.1136/ bmjopen-2018-028465

- Prepublication history and additional material for this paper are available online. To view these files, please visit the journal online (http://dx.doi. org/10.1136/bmjopen-2018028465).

Received 09 December 2018 Revised 13 August 2019 Accepted 16 August 2019

\section{Check for updates}

(c) Author(s) (or their employer(s)) 2019. Re-use permitted under CC BY-NC. No commercial re-use. See rights and permissions. Published by BMJ.

${ }^{1}$ Public Health and Primary Care, KU Leuven, Leuven, Belgium ${ }^{2}$ Public Health and Primary Care, University Leuven, Leuven, Belgium

Correspondence to Birgitte Schoenmakers; birgitte.schoenmakers@ kuleuven.be

\section{ABSTRACT}

Objective To find out if there is evidence on interventions to prevent aggression against doctors.

Design This systematic review searched the literature and reported in accordance with Preferred Reporting Items for Systematic Reviews and Meta-Analyses guidelines.

Data sources Pubmed, Embase, Turning Research into Practice (TRIP), Cochrane and Psycharticle, GoogleScholar and www.guideline.gov were consulted.

Eligibility criteria Abstracts published in English between January 2000 and January 2018 were screened. Eligible studies focused on prevention and risk factors of type II workplace violence in general healthcare, psychiatric departments, emergency departments, emergency primary care, general practice.

Data extraction and synthesis The selected intervention studies were grouped into quantitative and qualitative studies. Systematic reviews were reported separately. For each study, the design, type of intervention and key findings were analysed. Quality rating was based on Grading of Recommendations, Assessment, Development and Evaluation (GRADE) and GRADEConfidence in the Evidence from Reviews of Qualitative Research (CERQUAL).

Results 44 studies are included. One randomised controlled trial (RCT) provided moderate evidence that a violence prevention programme was effective in decreasing risks of violence. Major risk factors are long waiting times, discrepancy between patients' expectations and services, substance abuse by the patient and psychiatric conditions. Appropriate workplace design and policies aim to reduce risk factors but there is no hard evidence on the effectiveness. One RCT provided evidence that a patient risk assessment combined with tailored actions decreased severe aggression events in psychiatric wards. Applying de-escalation techniques during an aggressive event is highly recommended. Postincident reporting followed by root cause analysis of the incident provides the basic input for review and optimisation of violence prevention programmes.

Conclusions This review documented interventions to prevent and de-escalate aggression against doctors. Aggression against physicians is a serious occupational hazard. There is moderate evidence that an integrated violence prevention programme decreases the risks of patient-to-worker violence. The review failed to gather sufficient numerical data to perform a meta-analysis. A large-scale cohort study would add to a better understanding of the effectiveness of interventions.
Strengths and limitations of this study

- As compared with other reviews, this systematic review succeeded in inventorying and documenting all known interventions to prevent and de-escalate aggression against doctors.

- The literature search was performed through a wide range of available medical databases. Research in this area requires quantitative as well as qualitative methodological approaches and therefore both types of publications were included, focusing on violent incidence rates and on the why and how an intervention could work.

- The review failed to gather sufficient numerical data to perform a meta-analysis.

\section{INTRODUCTION}

Aggression against physicians including verbal, physical and psychological aggression is a well-known and serious occupational hazard. The prevalence of violence in healthcare is extensively documented in various settings and populations. Subjective interpretation of violent behaviour and under-reporting of workplace violence is consistently cited in literature.

A large, nationwide Australian study Balancing Employment and Life (MABEL) reported on the 12-month prevalence of verbal or written and physical aggression in Australian clinical medical practice: $70.6 \%$ of 9951 Australian doctors had experienced verbal or written aggression and $32.3 \%$ had experienced physical aggression in the previous 12 months. The 12-month prevalence of aggression towards general practitioners (GPs) was $54.9 \%$ for verbal aggression and $23.4 \%$ for physical aggression. ${ }^{1}$ In a survey in the UK $78 \%$ of all GPs experienced at least one verbal incident in the previous 2 years. ${ }^{2}$ A recent cross-sectional study among Flemish GPs showed that only about 5\% never encountered aggression. In most cases, the aggression was verbal, however, about $20 \%$ of the GPs reported physical aggression and almost $8 \%$ reported sexual aggression. ${ }^{3}$

A recent nationwide German survey reported that $91 \%$ of GPs had faced 
aggression at least once in their career and $73 \%$ in the previous 12 months. ${ }^{4}$ Typically, the highest rates of physical aggression were found in emergency departments (EDs) and in psychiatric units. A recent systematic review and meta-analysis showed a pooled incidence of 36 of every 10000 patient encounters in the ED of which $44 \%$ was associated with drug and alcohol exposure. ${ }^{5}$ More than a quarter of emergency physicians reported that they were victims of physical assault in the past year. ${ }^{6} \mathrm{~A}$ large randomised controlled trial (RCT) in a hospital setting identified between 8 and 15 reported violence events per 100 full-time equivalent staff members per year. ${ }^{7}$

In the healthcare setting, the most common type of workplace violence is where the aggressor is a patient or a relative of the patient. These events are categorised in literature as 'type II workplace violence'. Exposure to workplace violence can lead to physical and psychological injury, reduced job satisfaction and detachment, and affect the quality of care.

Although the impact of workplace-related aggression is considerable and well documented, there is no systematic evidence on how to prevent, intervene and approach hazardous situations. Despite the heterogeneity in scientific and event reports about workplace-related violence, there is consensus that safety action plans should be established and implemented. Therefore, the primary research question in this study is: 'What are interventions to prevent aggression against doctors in general and against the general practitioner in particular?'.

\section{METHODS}

This systematic review is performed according to Preferred Reporting Items for Systematic Reviews and Meta-Analyses guidelines. ${ }^{8}$ The risk of bias for randomised controlled studies was assessed and reported using the Cochrane classification scheme for bias. ${ }^{9}$

\section{Eligibility and inclusion criteria}

Abstracts published in English between January 2000 and April 2019 were screened for inclusion. Eligible studies focused on prevention of type II workplace violence: verbal, physical and psychological aggression from a patient or a patient's relative towards a healthcare worker. Studies focusing on 'aggression' by co-workers were excluded.

Qualitative and quantitative intervention studies were included. Systematic reviews and reviews on prevention strategies were included. Single case reports or opinion articles were excluded.

The target population was defined as healthcare workers in general healthcare, psychiatric departments, EDs, emergency primary care, general practice. Eligible interventions were focusing on risk factors, workplace violence prevention or strategies to reduce workplace violence. Comparison was defined as usual care and as strategy in case of reporting of a hazardous situation.
For evaluation of the effectiveness of interventions, the primary outcome was patient aggression towards healthcare workers. Secondary outcomes were risk factors, staff knowledge, staff skills and early detection of aggressive behaviour. The major findings were extracted and discussed as per the type of intervention.

\section{Search strategy}

Databases used were Pubmed, Embase, Turning Research into Practice (TRIP), Cochrane and Psycharticle with different search strategies (online supplementary appendix). The following search terms/Mesh terms were used: aggression, violence, physician, doctor, workplace, prevent*, strateg*, intervent*, general practitioner, health care. The reference list of articles was scanned additionally. A separate search was performed on Google Scholar and www.guideline.gov using the same search terms.

\section{Data collection and analysis}

The selected intervention studies were grouped into two groups: quantitative and qualitative studies. Systematic reviews were reported separately. For each selected study, the design, type of intervention and key findings were analysed. A level of evidence was attributed to each quantitative study based on the Oxford 2011 Levels of Evidence. ${ }^{10}$ Quantitative studies were rated according to GRADE. ${ }^{11}{ }^{12}$ For qualitative studies the GRADE-CERQUAL approach was used to assess quality. ${ }^{13}$

\section{Patient and public involvement}

Patients were not actively involved in this literature research. In a prior master thesis research, need assessment was conducted in general practice.

\section{RESULTS}

The total harvest of articles is presented in (online supplementary appendix 1). In total 105 full-text articles were read and assessed for eligibility. Forty-four studies (15 quantitative studies, 15 qualitative studies, 7 systematic reviews and 7 reviews) were included in this review (figure 1).

\section{Summary of results}

The results of the quantitative studies are presented in table 1 , the results of the qualitative studies in table 2. Table 3 summarises the systematic reviews and other reviews. Table 4 gives an overview of frequently cited guidelines. Table 5 summarises the factors that may increase the risk of workplace violence.

\section{Studies reporting on interventions}

The interventions most frequently discussed and evaluated are grouped. The first group of interventions was labelled as pre-event preventive measures: components of an integrated violence prevention programme. The second group was labelled as interventions taking place during a violent event: applying de-escalation techniques and activating specific violence emergency procedures. 

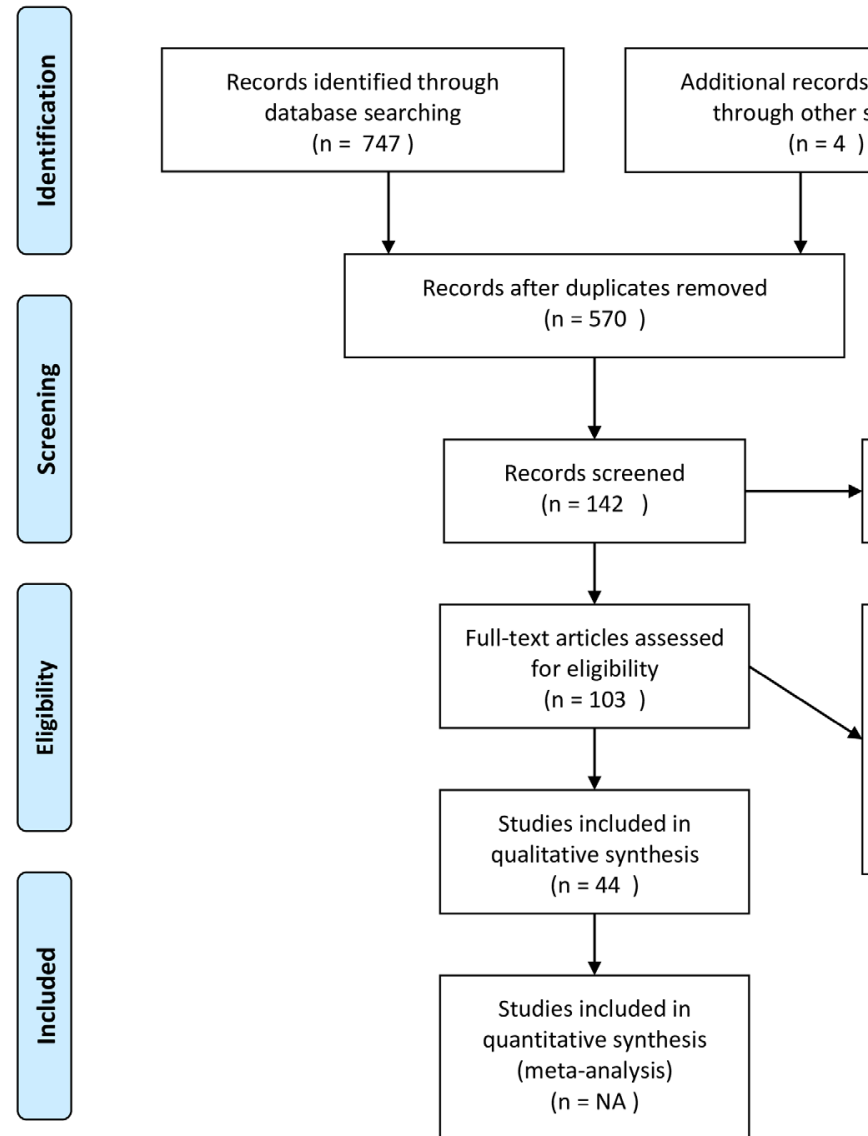

Records excluded $(n=39)$

Full-text articles excluded, with reasons ( $n=59$ ): . Studies focussing on harassment, stalking, violence or bullying by co-workers, reporting exclusively on the prevalence of Workplace Violence

Figure 1 Preferred Reporting Items for Systematic Reviews and Meta-Analyses (PRISMA) flow diagram of record screening and inclusion (adapted from Moher et al $\left[{ }^{8}\right]$ ).

The third group was labelled as postincident interventions: incident reporting followed by root cause analysis of the incident and review of the violence prevention policy.

\section{Pre-event preventive measures}

Under this label two types of interventions were identified: violence prevention programmes and risk assessment and control measures.

\section{Violence prevention programmes}

A variety of violence prevention programmes has been developed in order to prevent workplace violence and to manage and mitigate the impact of violence at work. All programmes propose an integrated approach incorporating basic elements such as a worksite risk analysis, hazard prevention and control measures, safety training and education, violent event reporting and evaluation. Some programmes explicitly apply the Plan-Do-Check-Act model of continuous quality improvement.

Arnetz et al investigated in a large RCT the effect of the Plan-Do-Check-Act model through a data-driven worksite-based intervention in 41 units across seven US hospitals over a period of 5 years. ${ }^{7}$ The study provided moderate evidence of this approach in decreasing risks of patient-to-worker violence and related injury at 6 months postintervention: the incident rate ratio (IRR) of violent events was significantly lower in intervention units compared with control units (IRR 0.48, 95\% CI 0.29 to 0.80 ). However, this effect was not confirmed over time during the 24-month follow-up period. At that time, only violence-related injury was lower in intervention units compared with control units (IRR 0.37, 95\% CI 0.17 to 0.83 ). Lipscomb et al evaluated in a 4-year study the impact of the implementation of the Occupational Safety and Health Administration (OSHA) guidelines and compared three intervention groups with three control groups in mental health facilities. ${ }^{14}$ Both the intervention and the control groups implemented safety preventions but the control group did not benefit from the additional support of the project team on violence prevention. The staff reported in both groups significant improvements in OSHA elements: management commitment, employee involvement and hazard assessment, and hazard control activities. Intervention facilities also reported significant 


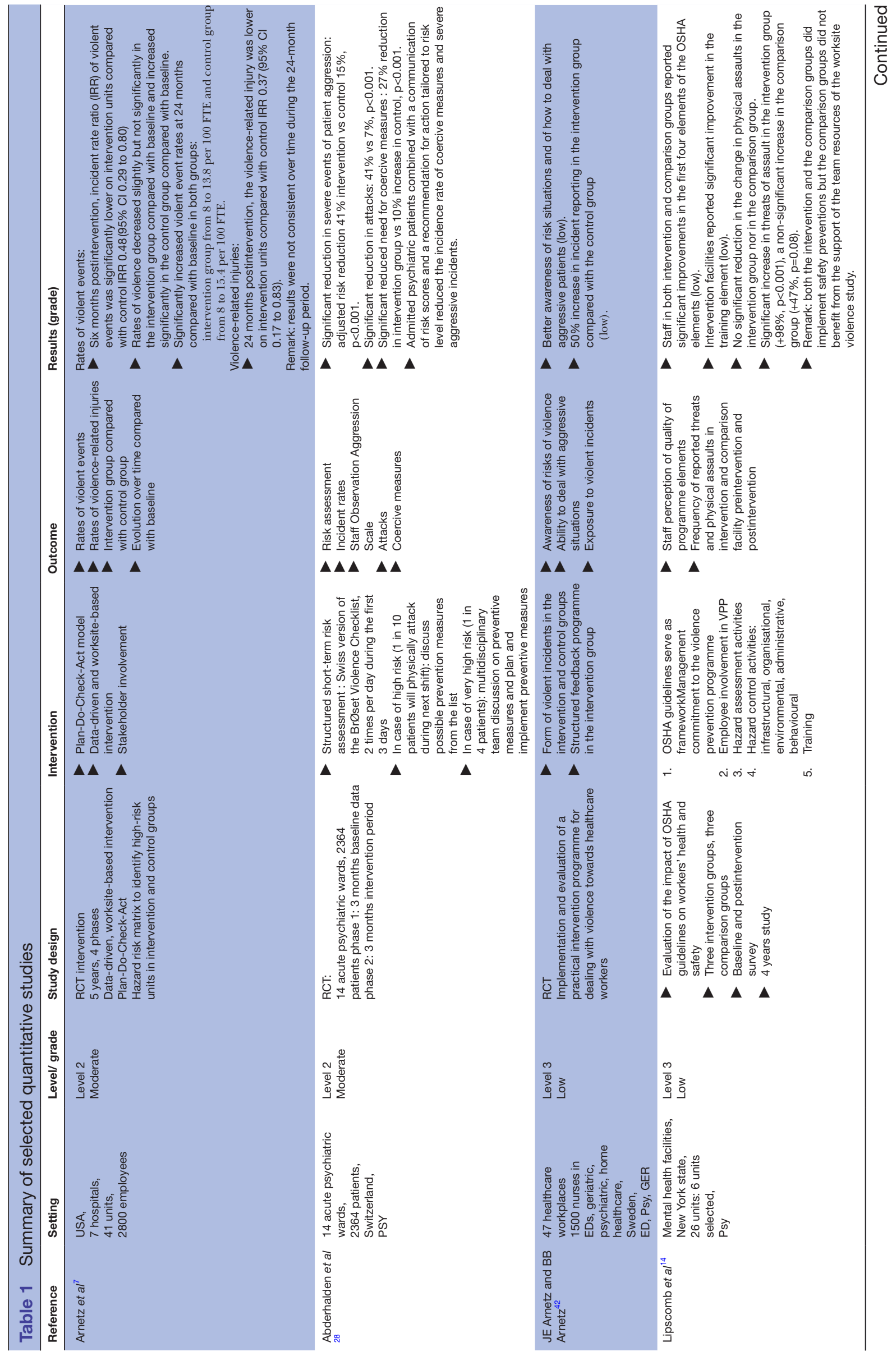




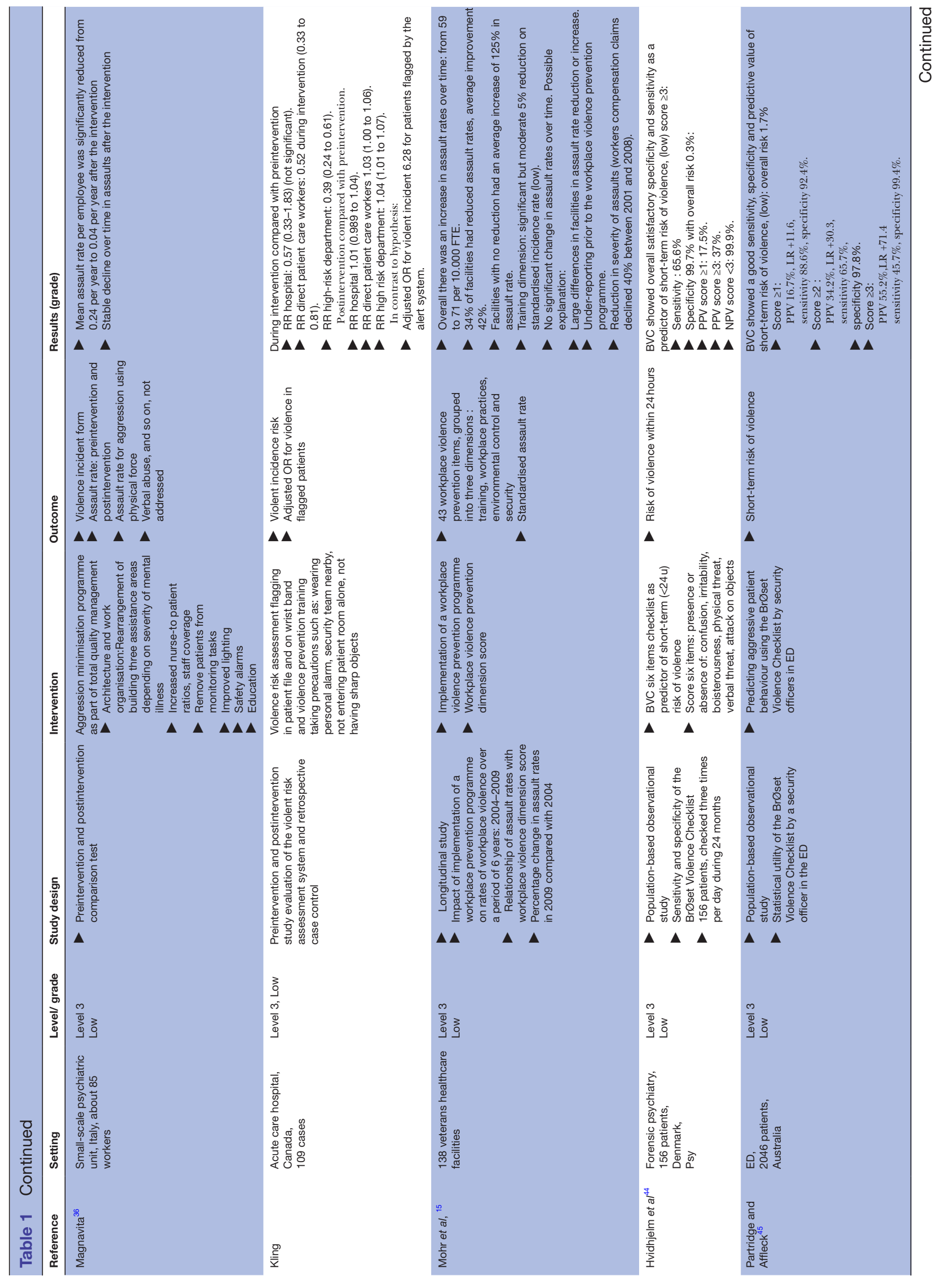




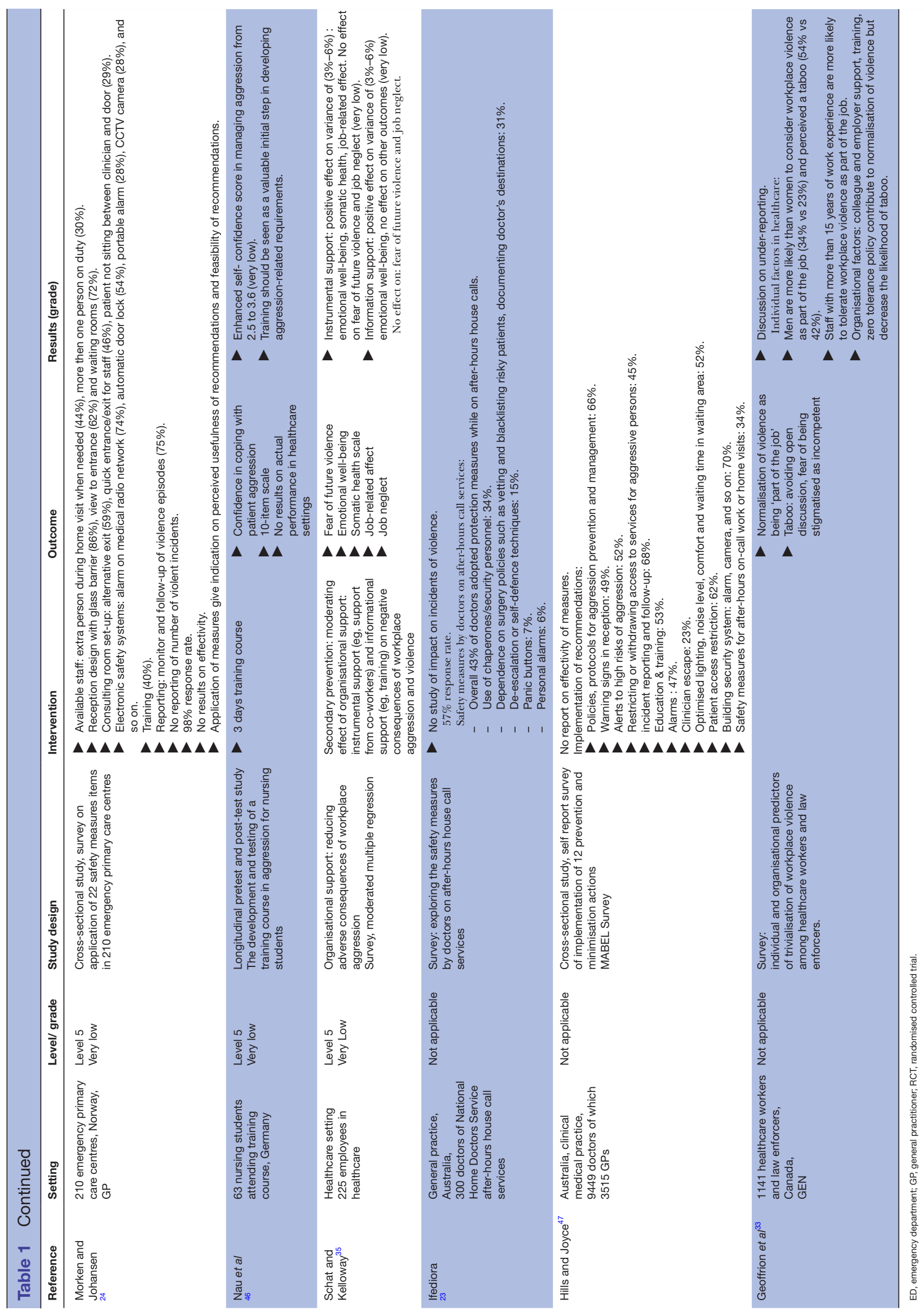



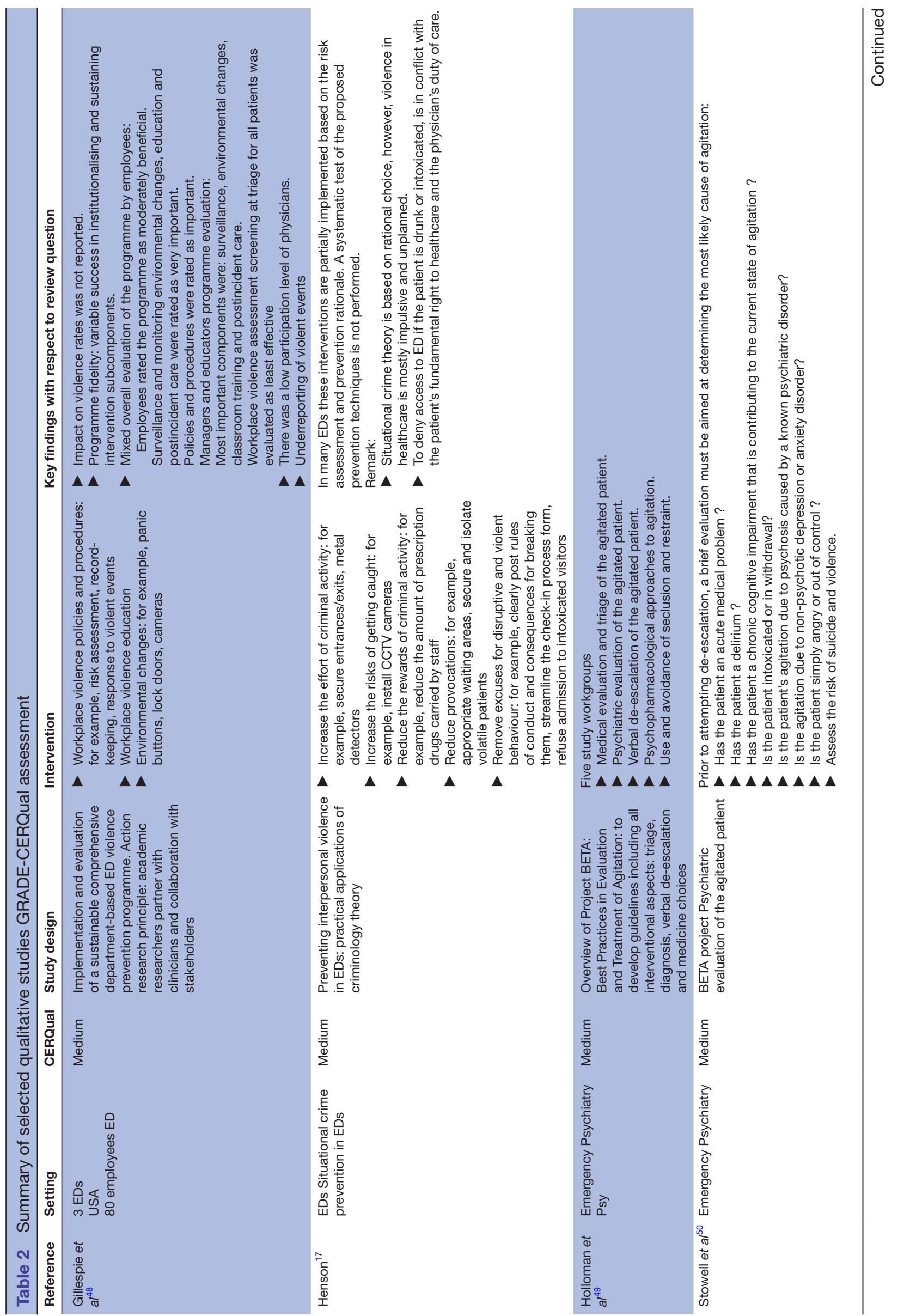

。 


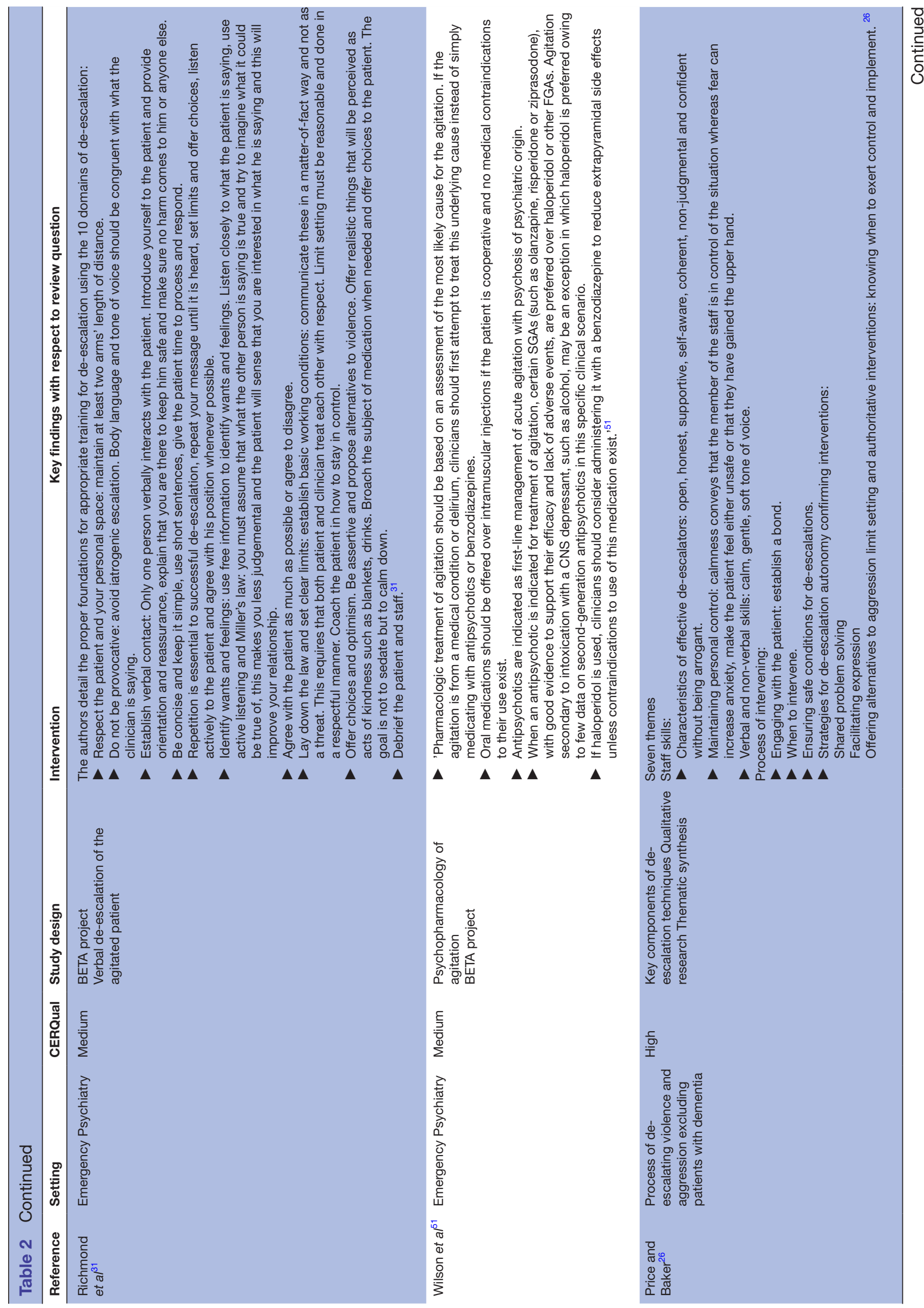




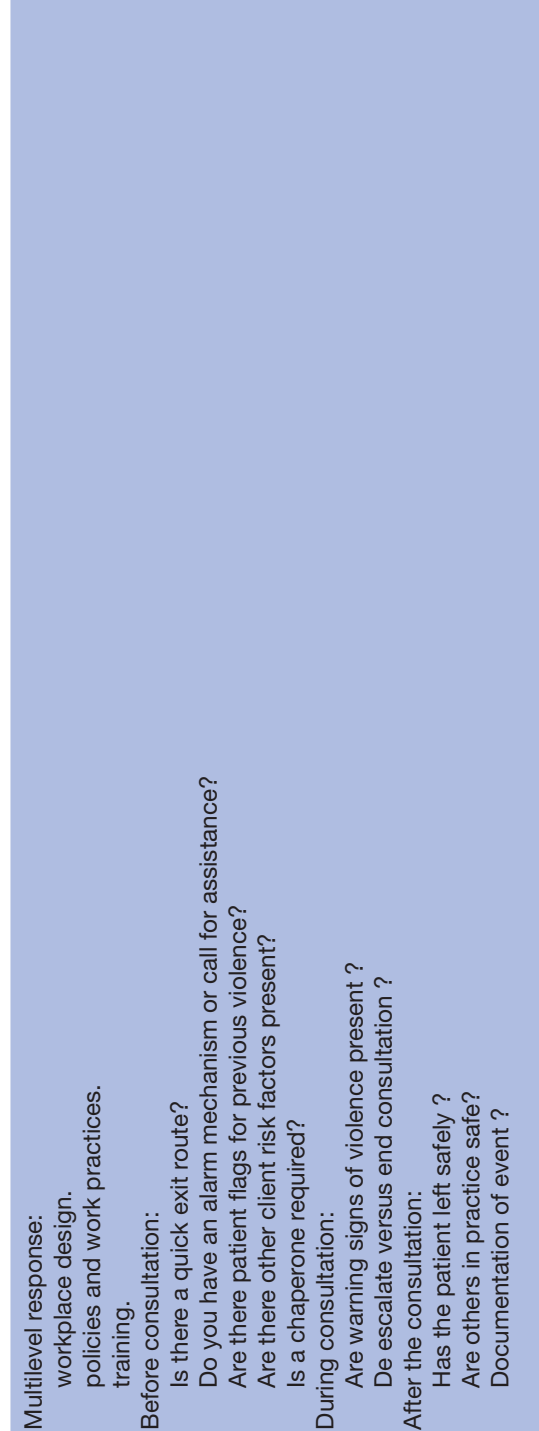

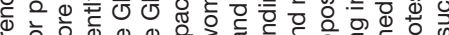
迹 흔

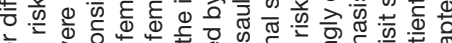

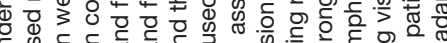

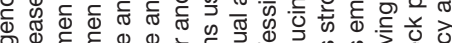

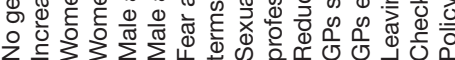

$\Delta \triangle \Delta \Delta \Delta \Delta$
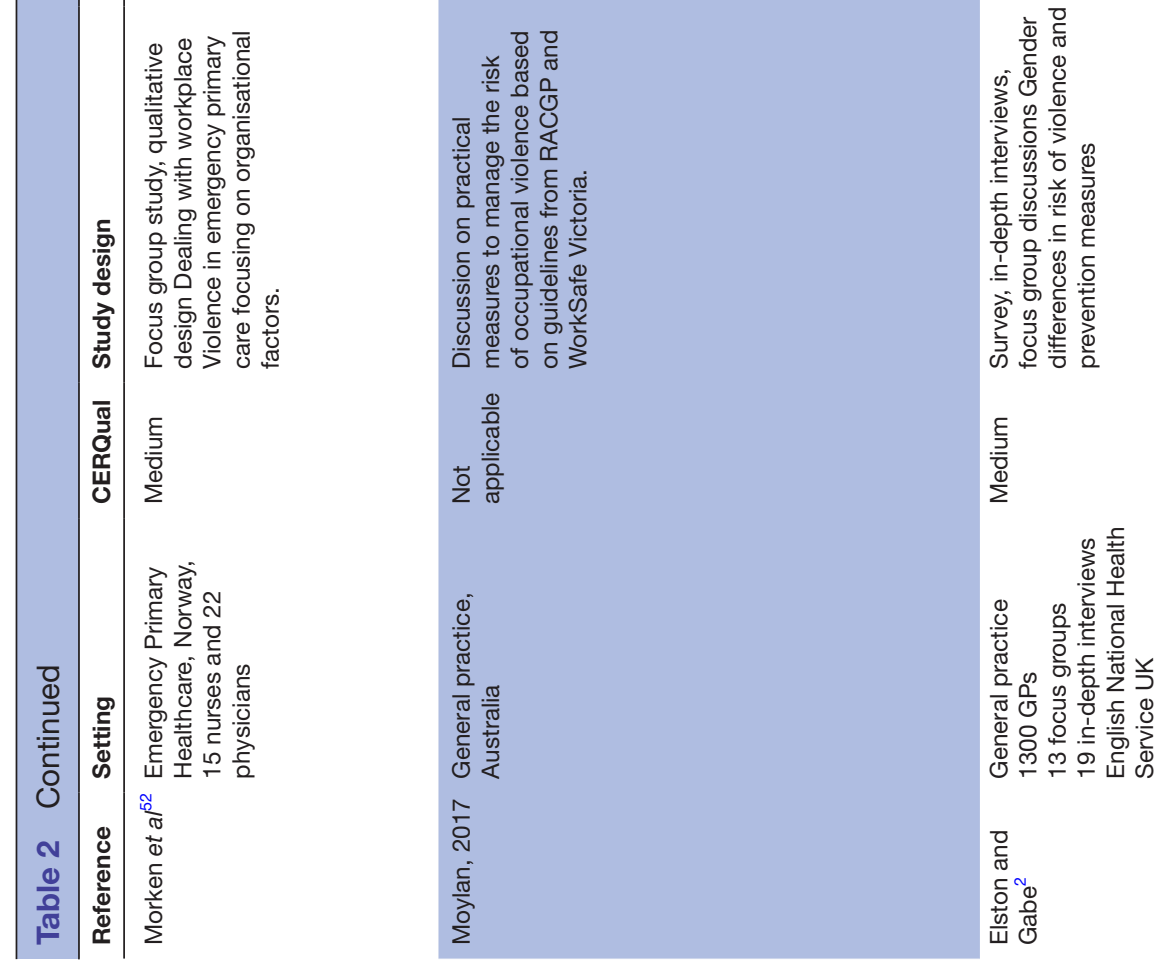


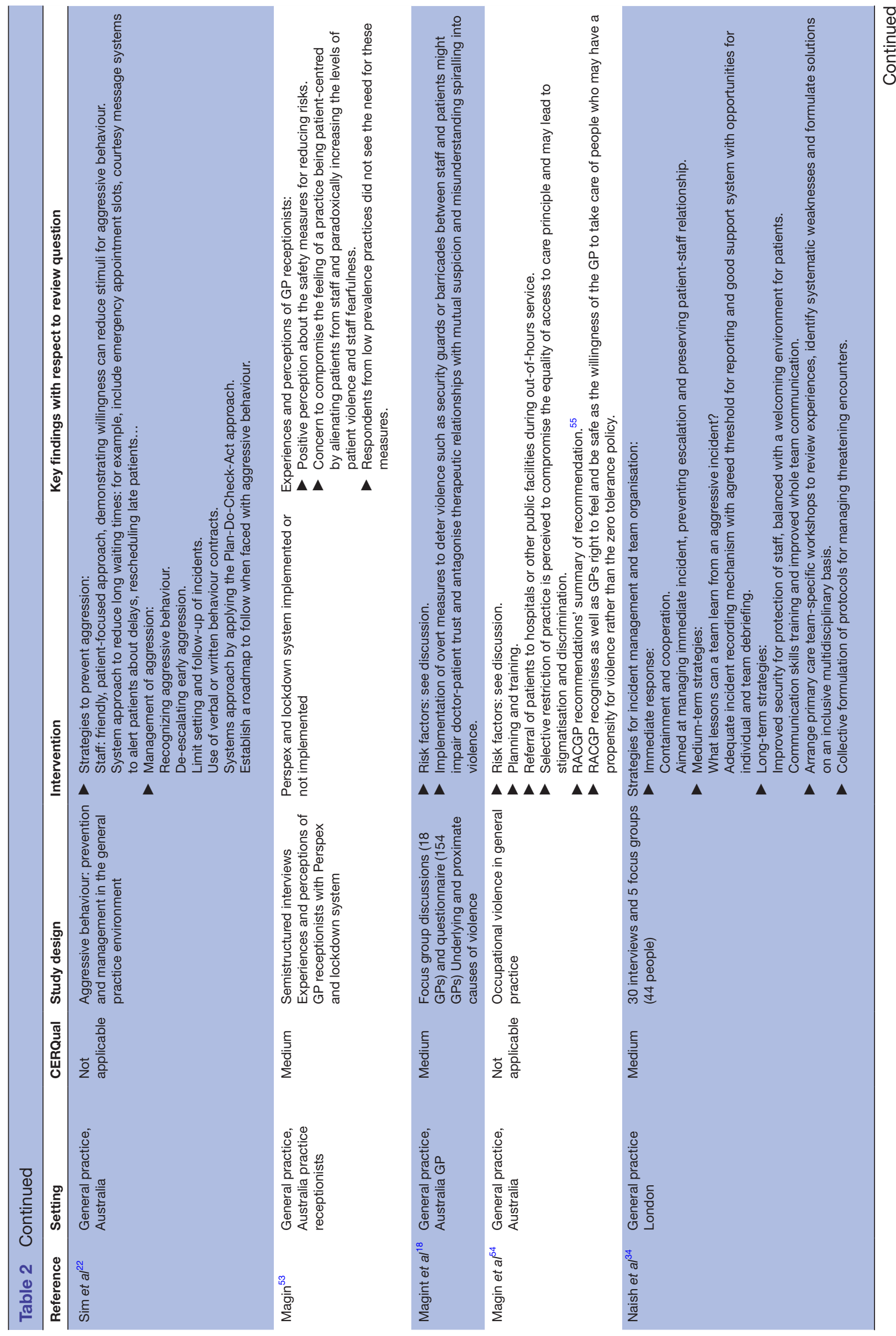



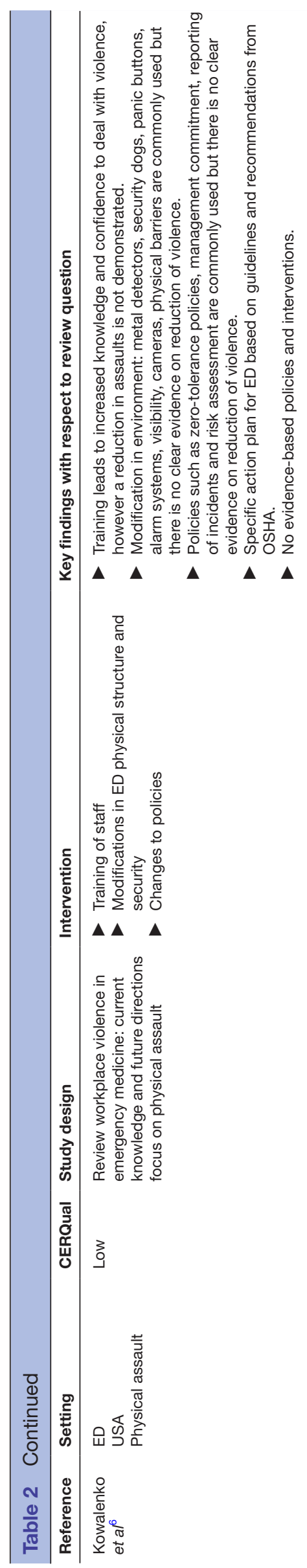

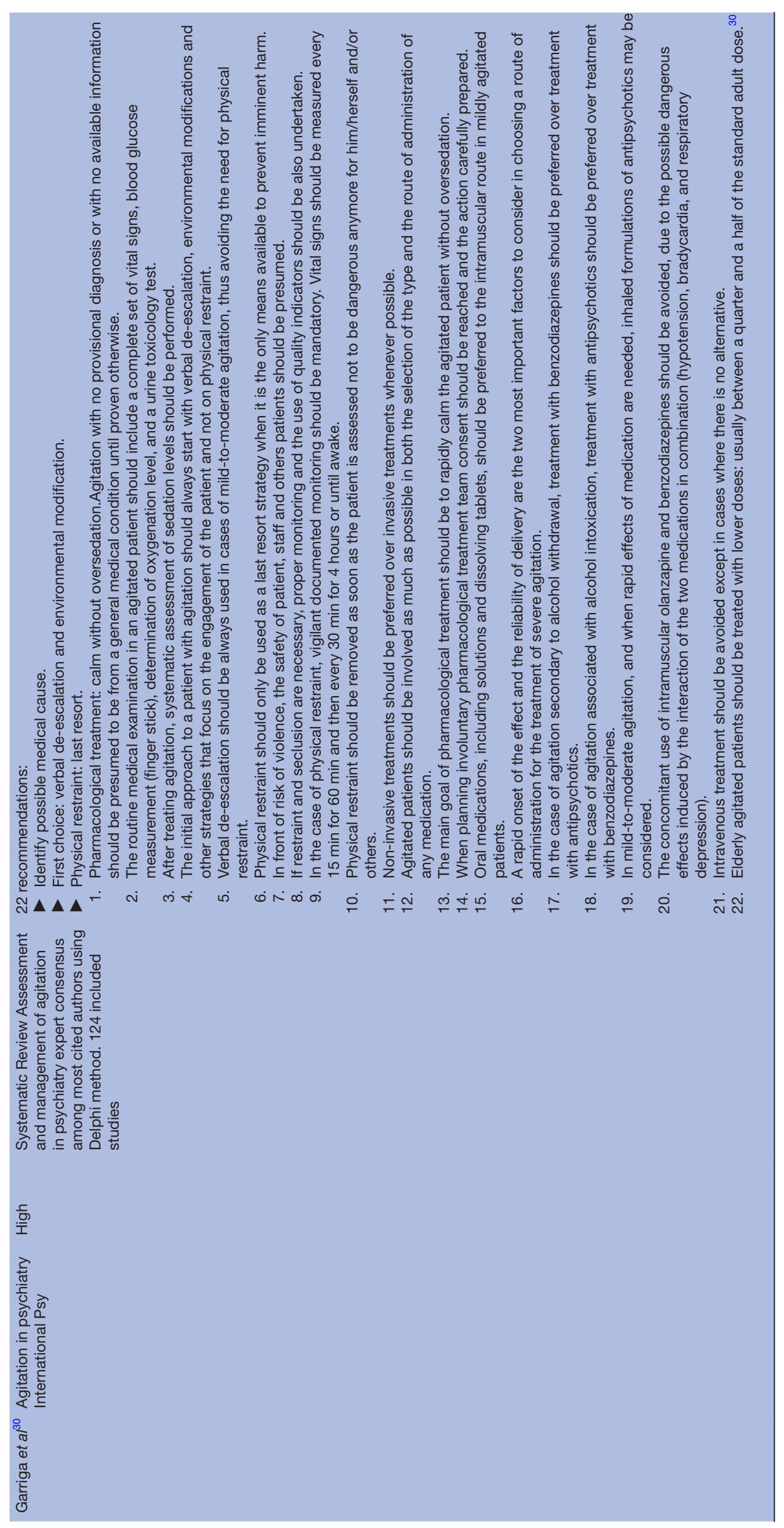




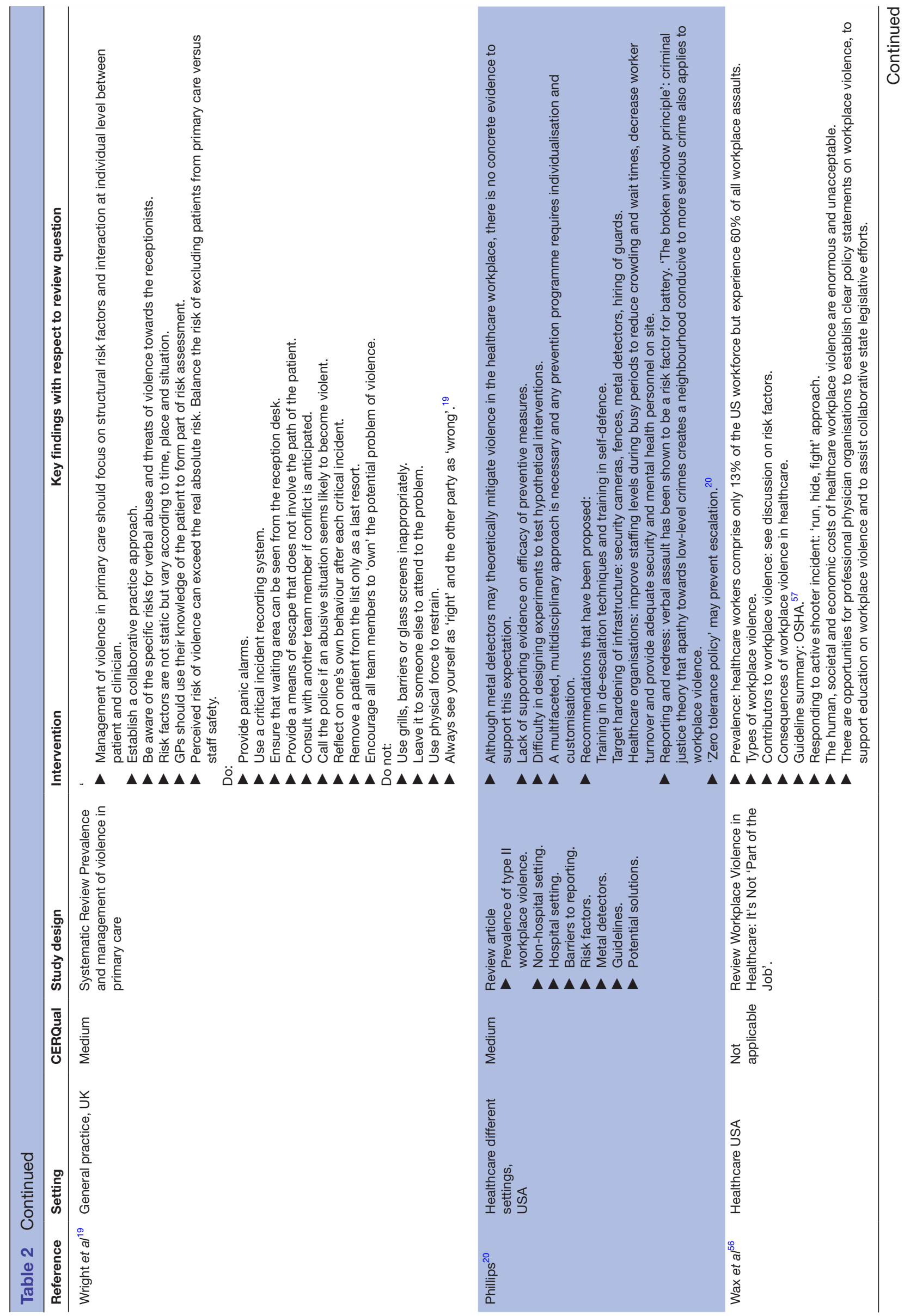




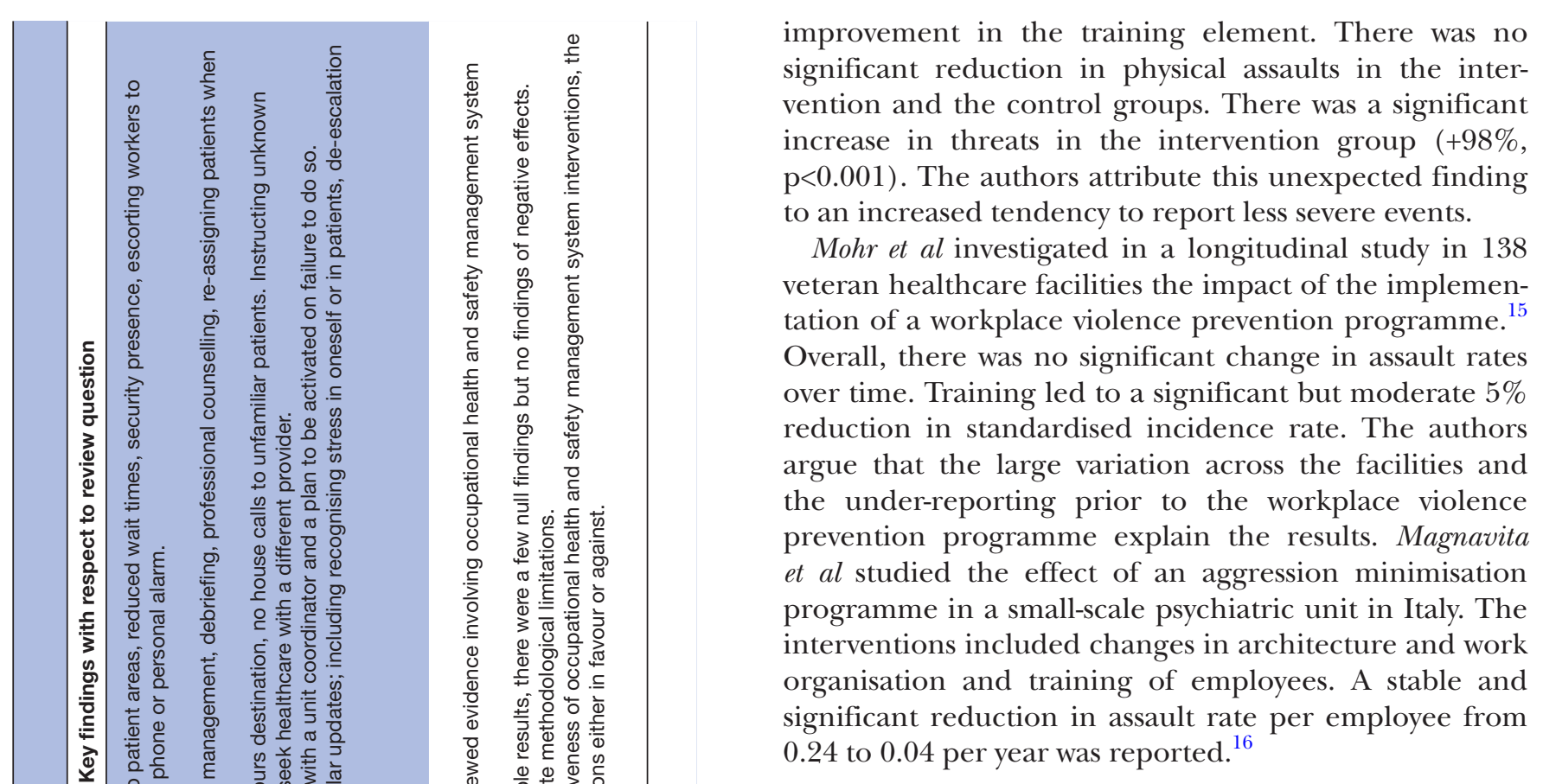

Risk assessment and risk control measures

Violence risk assessment and violence management are intrinsically connected. The risk factors can be categorised based on their source of origin: workplace design, work organisation, patient factors, physician factors and social context. Numerous studies confirmed the following items as main risk factors for aggression: long waiting times, discrepancy between patients' expectations and the services offered, alcohol or drug abuse by the patient, and psychiatric condition (table 5).

Subsequent to the specific violence risk assessment, the next step is applying appropriate risk control measures. Changes to the physical environment and work policies are based on situational crime prevention and aim to increase the effort of criminal activity, increase the risk of getting caught, reduce the rewards of criminal activity, reduce provocations and remove excuses for disruptive and violent behaviour. ${ }^{17}$

The proposed changes to physical environment vary across the different healthcare settings and include effective indoor and outdoor lighting, sufficient exit routes, physical barriers for receptionists, automatic door locks, video cameras, panic buttons, portable alarms and comfortable waiting areas to reduce stress. No concrete evidence exists on the effectiveness of these interventions. ${ }^{6}{ }^{18-21}$ In some emergency departments in USA, metal detectors have been installed, and although they may theoretically mitigate violence, there is no concrete evidence to support this assumption. ${ }^{6}$

Adequate work policies include 'zero tolerance' policies, incident reporting, training of staff, adequate staffing, policies on drug prescription and storage, a roadmap when faced with aggressive behaviour and additional measures for out-of-hours services. Drugs, cash and prescriptions should be stored in locked places and in limited amounts. Long waiting times should be 


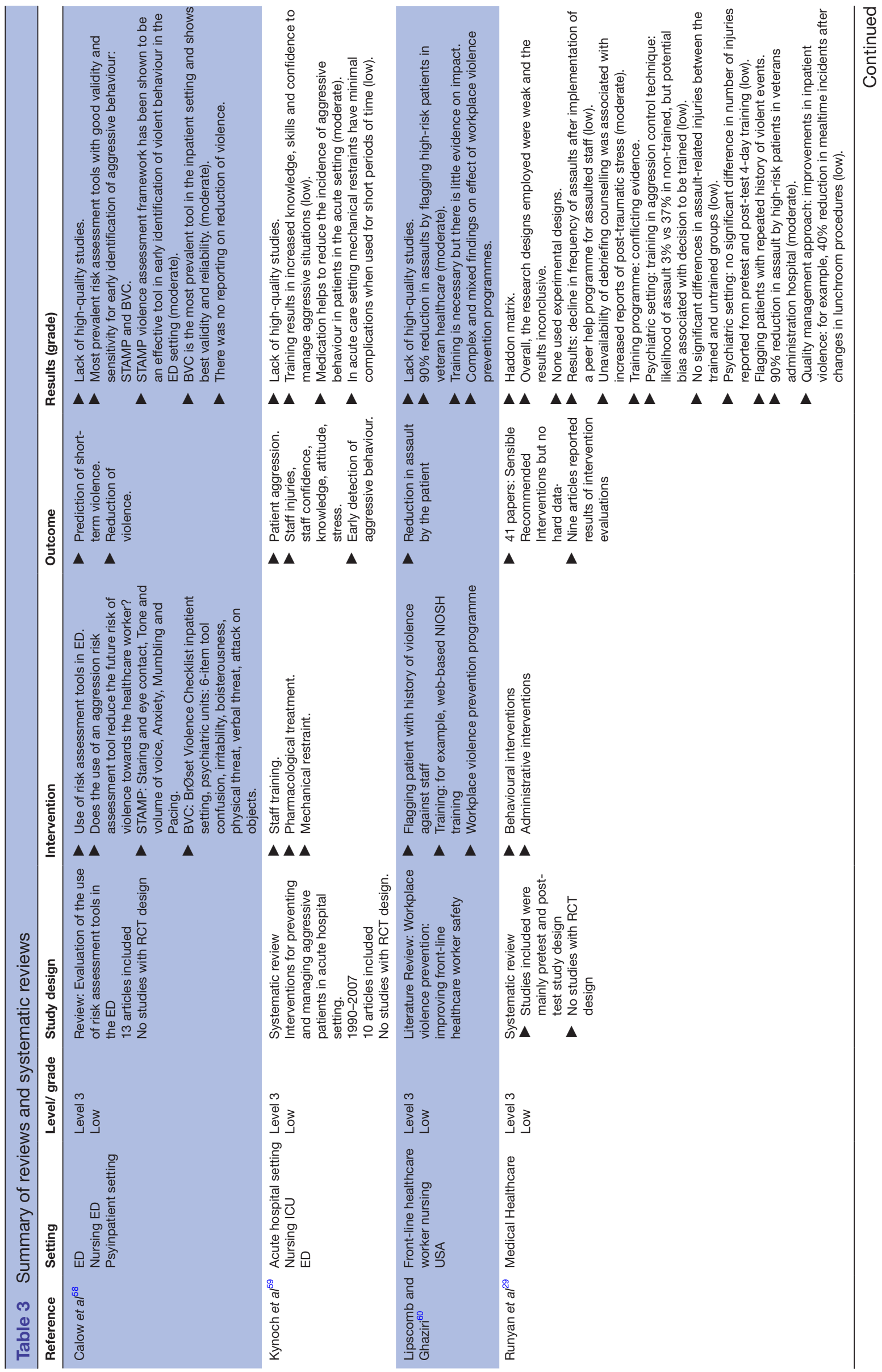




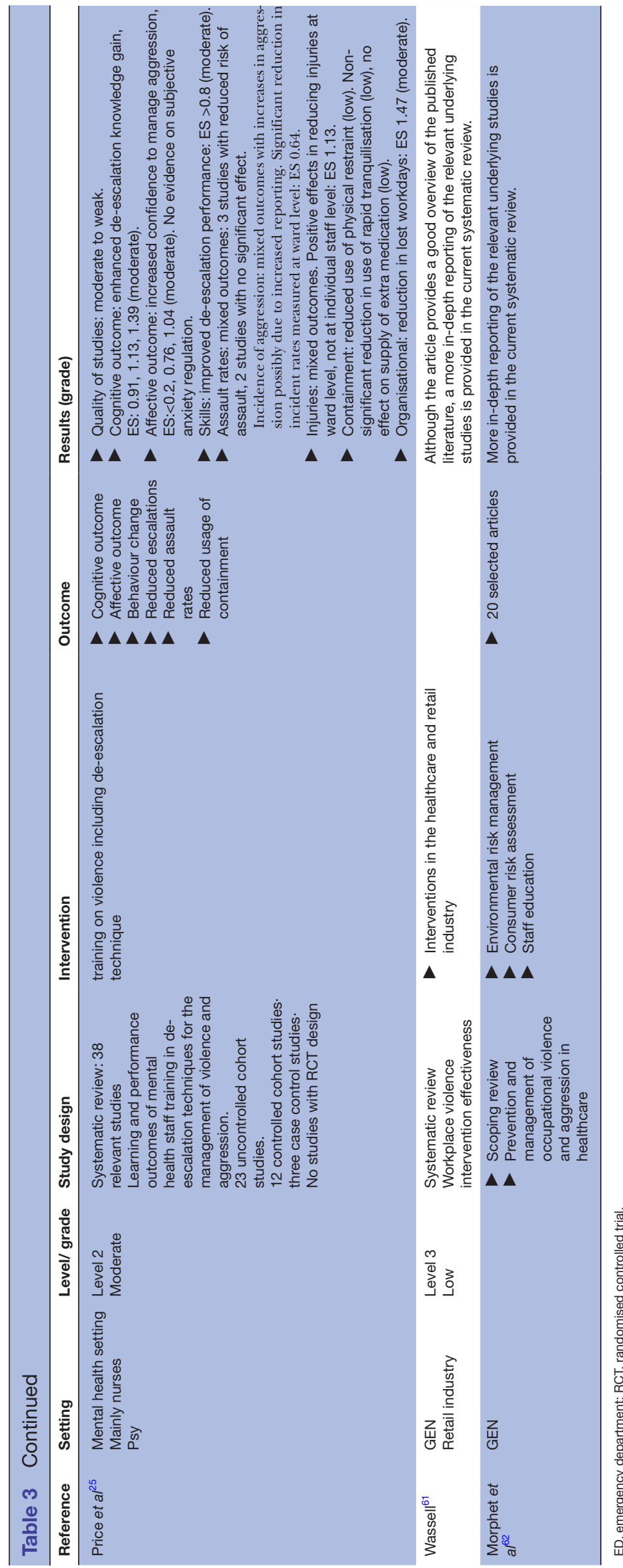

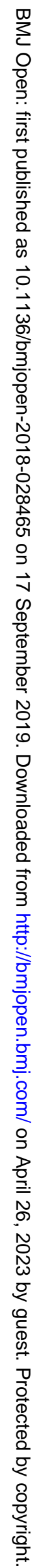


Table 4 Overview of relevant guidelines

\begin{tabular}{|c|c|c|}
\hline \multicolumn{2}{|l|}{ Guidelines } & \multirow{2}{*}{$\begin{array}{l}\text { Country } \\
\text { USA }\end{array}$} \\
\hline $\begin{array}{l}\text { Occupational Safety and Health } \\
\text { Administration, } 2016^{57}\end{array}$ & $\begin{array}{l}\text { Guidelines for preventing workplace violence for healthcare } \\
\text { and social service workers }\end{array}$ & \\
\hline Wiskow, $2003^{63}$ & Guidelines on workplace violence in the health sector & $\begin{array}{l}\text { Comparison of different } \\
\text { guidelines }\end{array}$ \\
\hline $\begin{array}{l}\text { The Royal Australian College of } \\
\text { General Practitioners, } 2015^{55}\end{array}$ & $\begin{array}{l}\text { General practice-a safe place } \\
\text { A guide for the prevention and management of patient- } \\
\text { initiated violence }\end{array}$ & Australia \\
\hline NICE, $2015^{65}$ & $\begin{array}{l}\text { Violence and aggression: short-term management in mental } \\
\text { health, health and community settings }{ }^{65}\end{array}$ & UK \\
\hline $\begin{array}{l}\text { FOD Binnenlandse Zaken and } \\
\text { FOD Volksgezondheid, } 2009^{66}\end{array}$ & een veilige dokterspraktijk & Belgium \\
\hline
\end{tabular}

managed by expanding the staff during busy periods and by setting up courtesy message systems to alert patients about delay. ${ }^{20} 22$ Some guidelines and studies propose a 'zero tolerance policy' with explicit statements and warning signs stating that violence will not be tolerated. It is important to recognise verbal assault as a form of workplace violence since it is a risk factor for physical violence. ${ }^{20}$ Some authors advise to restrict or withdraw access to general practice or emergency department services for patients with a history of violence. ${ }^{17}$ However, this also might compromise the 'equality of access to care' principle and there is no evidence of the impact on violence reduction. GPs should take additional measures for after-hours house call services such as using a central dispatch centre or a shared visit schedule and tracking system. Additional support might be provided in certain circumstances or on request of the GP.

Ifediora et al investigated the implementation of safety measures by GPs on after-hours call services in Australia: overall $43 \%$ of the doctors adopted protection measures and for after-hours house calls, 34\% used additional chaperones or security personnel. The study did not investigate the impact of these measures on violence incidents. ${ }^{23}$ Morken et al investigated in a cross-sectional study the implementation of 22 safety recommendations in 210 emergency primary care centres in Norway. The study provided evidence on the perceived usefulness and feasibility of the recommendations. ${ }^{24}$

Training of staff in communication skills, violence and de-escalation techniques should be included in a comprehensive violence prevention programme. Effective training on de-escalation should focus on cognitive, affective and practical skills based improvements in behaviour and reaction in case of an assault. Self-awareness and the ability to connect interpersonally with the aggressor are crucial. Price et al investigated in a systematic review, the cognitive and affective outcome and the effectiveness of training on violence. There is currently limited evidence that this training has an effect on de-escalation of aggressive behaviour. ${ }^{25}$ As discussed hereafter, de-escalation is a highly specialised intervention and this might explain the limited effectiveness of the training programmes. ${ }^{26}$

With respect to patient risk factors, the risk of violence is dynamic and contextual. ${ }^{27}$ Violence in medical healthcare is mostly impulsive and accompanied by the fightflight response although premeditated aggression also occurs. Risk assessment tools focusing on patient aggression have shown to be effective as a predictor for shortterm violence. Abderhalden et al investigated in an RCT the use of short-term risk assessment in 14 acute psychiatric wards in Switzerland. The intervention consisted of structured risk assessment twice a day followed by communication of risk scores and recommendation for actions tailored to the risk level. The study showed a significant reduction in severe events of patient aggression, a significant reduction in attacks and a significantly reduced need for coercive measures. ${ }^{28}$ Flagging patients with a history of violent events resulted in $90 \%$ reduction in assaults by high-risk patients in veteran healthcare hospitals in USA. $^{29}$

\section{Interventions during the event}

During the event of violence the following recommendations are described in the guidelines: stay calm and apply de-escalation techniques, if de-escalation fails, take care of your own safety, go away or use self-defence techniques and activate the emergency procedure (references in table 4).

The use of restrictive interventions should only be applied in accordance with pre-established protocols and in a manner that complies with the human rights.

De-escalation is, in the medical care sector and in other settings, a highly recommended component of violence prevention. Garriga et al (Table 3) carried out a systematic review on assessment and management of agitation in psychiatry. ${ }^{30}$ After identification of possible medical 
Table 5 Risk factors that increase the risk of occupational violence $418-2230335254566068-71$

\begin{tabular}{|c|c|}
\hline Workplace design & $\begin{array}{l}\text { Poor delineation between staff-only area and patient area } \\
\text { Lack of controls in accessing staff-only and patient areas } \\
\text { Overcrowded, uncomfortable or noisy waiting rooms } \\
\text { Poor access to exits, toilets and amenities } \\
\text { Poor lighting, blind spots without surveillance } \\
\text { Unsecured furnishings that can be used as weapons }\end{array}$ \\
\hline Policies and work practices & $\begin{array}{l}\text { Increased waiting times } \\
\text { Poor customer services from staff } \\
\text { Deficit in staffing levels or inadequate skills mix } \\
\text { Working alone } \\
\text { Lack of violence-prevention programmes } \\
\text { Lack of staff empowerment and shared governance } \\
\text { Lack of follow-up of violent episodes by management } \\
\text { Poor safety culture: 'broken window principle' } \\
\text { Ineffective mechanisms to warn and ultimately deny service to patients with repeated behaviours of concern } \\
\text { Lack of staff training in de-escalation techniques } \\
\text { Lack of staff training in aetiology and treatment of various pathologies associated with violent behaviour } \\
\text { Use of physical restraints } \\
\text { Mismatch between expectations and services offered: for example, demands for classified drugs } \\
\text { Presence of drugs, cash or valuable items in the office } \\
\text { Refusal to provide a prescription or a sickness or disability certificate } \\
\text { On-call shifts/house visits }\end{array}$ \\
\hline Patient factors & $\begin{array}{l}\text { Current illness with physiological imbalances or disturbances: } \\
\text { Head trauma } \\
\text { Encephalitis, meningitis, infection } \\
\text { Encephalopathy } \\
\text { Metabolic derangement: Hyponatraemia, hypocalcaemia, hypoglycaemia } \\
\text { Hypoxia } \\
\text { Thyroid disease } \\
\text { Seizure (postictal) } \\
\text { Exposure to environmental toxins } \\
\text { Toxic levels of medications } \\
\text { Active intoxication, substance dependence, misuse or abuse } \\
\text { Psychosocial stressors } \\
\text { Previous poor experiences with healthcare services } \\
\text { Past history of violence } \\
\text { Psychiatric disorder } \\
\text { Personality, interpersonal style of control or dominance } \\
\text { Frustration, perception not being respected, not being listened to or being treated unfairly } \\
\text { Stress, agitation } \\
\text { Loss of situational control } \\
\text { Unexpected or high costs of healthcare } \\
\text { Complex family relationships }\end{array}$ \\
\hline Physicians factors & $\begin{array}{l}\text { Being unprepared } \\
\text { Lack of education and training on violence: being unaware of own body language, not knowing how to de-escalate, } \\
\text { not knowing how to escape } \\
\text { Inadequate medical skills } \\
\text { Poor communication skills } \\
\text { Less years of experience } \\
\text { Physicians own emotions, anger, anxiety, countertransference } \\
\text { Overworked, stressed } \\
\text { Interpersonal style: for example, assertive style by the physician may challenge the patient's sense of dominance and } \\
\text { lead to discomfort and frustration } \\
\text { Gender: no difference in overall risk of violence, increased risk within younger, male GPs for physical assaults } \\
\text { Vulnerability in being a source of risk with respect to legal or licensing matters, for example, with information to third } \\
\text { parties beyond direct patient care } \\
\text { Vulnerability : where does the duty of care end in the face of potential violence? } \\
\text { Personality traits with increased risk: low agreeableness, high neuroticism, high negative affect, low extroversion, low } \\
\text { conscientiousness, low self-esteem }\end{array}$ \\
\hline Societal causes/social context & $\begin{array}{l}\text { Poverty, unemployment and social dislocation } \\
\text { Reduced respect for authority, patients are having a greater sense of entitlement than in the past and as a } \\
\text { consequence frustration in not getting response to demands potentially leads to violence } \\
\text { 'Bowling for Columbine effect': spiral of fearfulness, suspicion leading to pre-emptive defensiveness, confrontation } \\
\text { and ultimately a greater risk of violence } \\
\text { Population density } \\
\text { Language barriers } \\
\text { Cultural differences }\end{array}$ \\
\hline
\end{tabular}

GP, general practitioner.

causes for agitation, verbal de-escalation and environmental modification are first-choice interventions.

As established by Richmond et al, de-escalation can be successful in less than $5 \mathrm{~min}$. Non-coercive de-escalation is executed in a three-step approach: first, the patient is verbally engaged, second, a collaborative relationship is established and third, the patient is verbally de-escalated out of the agitated state. ${ }^{31}$ De-escalation frequently takes 
the form of a verbal loop in which the clinician listens to the patient, finds a way to respond acknowledging the patient's position and then states what he wants the patient to do. The clinician might have to repeat the loop a dozen or more times and inexperienced clinicians tend to give up. ${ }^{26}$

Similar principles of de-escalation have also been described by Kohlrieser, a psychologist and hostage negotiator. $^{32}$

\section{Postincident measures}

As studied by Geoffrion et al individual and organisational factors can lead to trivialisation of workplace violence, a culture of silence and under-reporting of workplace violence. Two aspects play a role in trivialisation of workplace violence: normalisation of violence as being 'part of the job' and taboo by avoiding an open discussion out of fear of being stigmatised as incompetent. Colleague and employer support, training on violence, zero tolerance policy all, contribute to normalisation of violence and decrease the likelihood of taboo. Organisations should be aware of this paradox implicitly arisen by sending the message that violence is to be expected..$^{33}$

Reflecting on incidents or performing a root cause analysis in team-specific workshops can identify systematic weaknesses and potential solutions, action plans and revision of the workplace violence policy. ${ }^{34}$

Organisations should provide support and assistance to victims and address short-term and long-term consequences. Schat et al investigated the effect of organisational support in reducing the negative consequences of workplace violence and found a small positive effect on emotional well-being, somatic health and job-related affect but there was no effect on fear of future violence and on job neglect. ${ }^{35}$

\section{DISCUSSION}

\section{Summary of main results}

This review demonstrated that only few studies have been successful in providing evidence on the efficacy of interventions to prevent aggression against doctors and more specifically against the GP. Only one RCT provided moderate evidence that a violence prevention programme was effective in decreasing the risks of patient-to-worker violence and of related injury. ${ }^{7}$ In contrast, longitudinal studies showed conflicting results in assault rates after implementation of a workplace violence prevention programme. ${ }^{1529} 36$ Appropriate workplace design and work policies aim to reduce risk factors for violence such as long waiting times and crowded waiting areas but there is a lack of evidence on the effectiveness of the interventions. ${ }^{6}{ }^{19-21}$ During the event of violence or agitation, applying de-escalation techniques is a highly recommended component of violence prevention. Physical restraint should be considered as a last resort strategy. ${ }^{30}$ Postincident interventions such as incident reporting followed by a root cause analysis of the incident provides the basic input for review and optimisation of the violence prevention programme.
This review included quantitative and qualitative studies, focusing on violence incidence rates and on why and how an intervention works. Although there is a lack of hard evidence on the effectiveness of occupational health and safety management systems, there is a wide consensus that the implementation of a comprehensive health and safety prevention plan is the key to understanding, preventing and dealing with workplace violence ${ }^{37}$ As stated by James in his book Violence Assessment and Intervention: 'Preparation is critical as long as you accept that whatever you plan for and however you plan for it to occur, will never happen. Preparation is the 'primer' to get you propelled toward resolve and is important in addressing a crisis. ${ }^{38}$

A work site-specific violence risk assessment provides the basic input for interventions. The focus of prevention and intervention goes to both the clinician and to logistics or infrastructure. Major risk factors for violence are long waiting times, discrepancy between patients' expectations and the services offered, alcohol or drug abuse by the patient or a psychiatric condition. Specific risk control measures on the policy level to ensure adequate staffing and to reduce waiting times and training personnel in de-escalation seem rational interventions even without hard evidence.

The dynamic nature of risks feeds the issue of unintended consequences or the 'intervention dilemma'. This dilemma states that any intervention has the capacity to either reduce the risk or not affect it or even intensify the risk. ${ }^{27}$ On the level of workplace design and work policies, $100 \%$ security will never be obtained. A balance has to be made between safety and quality of life and quality of care. ${ }^{38}$ Some interventions proposed to increase safety might be in conflict with the goals of healthcare. For example, a zero tolerance policy or flagging patients with violent history can lead to stigmatisation of the patient and can be in conflict with patient confidentiality and the right to medical care. Implementation of overt measures such as security guards or barricades between staff and patients might impair the doctor-patient relationship, which can lead to a spiral of fearfulness and suspicion and ultimately to an increased risk on violence. Evidence suggests that individuals carrying an increased risk for violent behaviour are not violent at all times or in all situations. ${ }^{19}$

De-escalation, if undertaken with a sincere commitment and with the goal of 'helping the patient calm himself' proved to be successful in far more cases than previously assumed and this strategy can be successful in less than 5 min. ${ }^{30}$ De-escalation is a complex and time-consuming intervention and this might explain the limited effectiveness of the training programmes. ${ }^{26}$

Under-reporting is a well-known issue in workplace violence management. It is partly due to normalisation of violence as being part of the job and to the taboo associated with complaining about violence. Under-reporting is also influenced by the interventions themselves and complicates research outcome and the interpretation of results.

Victims of type II workplace violence should be assisted and supported by their organisation and short-term and long term consequences should be addressed..$^{35}$ A decline 
in frequency of assaults occurs after implementation of a peer help programme for assaulted staff. ${ }^{39}$ The unavailability of debriefing is associated with increased reports of post-traumatic stress. ${ }^{40} 41$

\section{Limitations}

The first limitation lies in the risk of bias across studies since mainly English and some French, German and Dutch publications were screened. Second, research on workplace violence is published in the traditional international medical scientific literature databases. The second limitation is the publication date, the literature search started in 2000. This starting time was chosen ad random. To compensate however for any loss of data before this date, the very comprehensive review of Runyan et al, published in the year 2000 was included in the analysis of this review. The third limitation lies in the risk of bias within studies. Only three RCTs are included in this review. ${ }^{72}{ }^{42}$ Performance bias, detection bias and reporting bias are present in all studies. Due to the nature of the problem and of the interventions, allocation concealment, blinding of participants and blinding of outcome is not possible. Also as discussed in this review, under-reporting and selective reporting, a wellknown issue in workplace violence, is variably present in all studies and is influenced by the intervention itself. ${ }^{7}$ Recall bias is also present due to data collection inquiring about violent events over the past 12 months. ${ }^{42}$ Finally, performance bias is present in all studies through various mechanisms: a medical care setting is a complex structure and organisational changes might have an impact on care quality and on safety performance and might interfere as a co-intervention. ${ }^{43}$ Moreover, in all RCTs, the control group will always have its own safety prevention policy.

\section{Suggestions for further research}

We believe that a large and long-term cohort study could provide more insight and evidence on effective interventions to prevent aggression against the GP. Risk factors for type II workplace violence are well known but there are insufficient data on protective factors for aggression against doctors. Analysis of large data sets of a cohort should provide insight in the protective factors and effectiveness of interventions against type II workplace violence.

A yearly audit on context of aggression incidents and on the applied safety measures per general practice will add to map effective preventive measures. Basic information about recommended safety prevention measures and training on de-escalation techniques should be offered to the cohort. With respect to postevent interventions, the GPs in the study cohort could implement a shared violence incident-reporting tool.

\section{CONCLUSION}

Aggression against physicians is a well-known and serious occupational hazard. There is moderate evidence that an integrated violence prevention programme can decrease the risks of patient-to-worker violence. Appropriate workplace design and work policies aiming to reduce risk factors and applying de-escalation techniques during an event of aggression are highly recommended. Considering that detection, reporting and performance bias are inherent to any RCT on interventions against type II workplace violence, we believe that a large cohort study would provide more evidence on the effectiveness of the interventions.

Contributors AR: setting up the design and method, data acquisition and analysis, interpretation of data, drafting the paper, approving the final version, accountable for the entire work. BS: delivering the research question, supporting, reviewing and revising the research process, performing data quality check, revising the manuscript for publication, accountable for both the work and the researcher.

Funding The authors have not declared a specific grant for this research from any funding agency in the public, commercial or not-for-profit sectors.

Competing interests None declared.

Patient consent for publication Not required.

Provenance and peer review Not commissioned; externally peer reviewed.

Data availability statement Data are available upon reasonable request.

Open access This is an open access article distributed in accordance with the Creative Commons Attribution Non Commercial (CC BY-NC 4.0) license, which permits others to distribute, remix, adapt, build upon this work non-commercially, and license their derivative works on different terms, provided the original work is properly cited, appropriate credit is given, any changes made indicated, and the use is non-commercial. See: http://creativecommons.org/licenses/by-nc/4.0/.

\section{REFERENCES}

1. Hills DJ, Joyce CM, Humphreys JS. A national study of workplace aggression in Australian clinical medical practice. Med J Aust 2012;197:336-40.

2. Elston MA, Gabe J. Violence in general practice: a gendered risk? Sociol Health IIIn 2016;38:426-41.

3. Demeur V, Devos S, Jans E. Agressie tegen de huisarts: de arts in nood. Het profiel van de kwetsbare huisarts. Ku Leuven, 2017.

4. Vorderwülbecke F, Feistle M, Mehring M, et al. Aggression and violence against primary care physicians - a nationwide questionnaire survey. Dtsch Arztebl Int 2015;112:159-65.

5. Nikathil S, Olaussen A, Gocentas RA, et al. Review article: workplace violence in the emergency department: a systematic review and meta analysis. Emerg Med Australas 2017;29:265-75.

6. Kowalenko T, Cunningham R, Sachs CJ, et al. Workplace violence in emergency medicine: current knowledge and future directions. $J$ Emerg Med 2012;43:523-31.

7. Arnetz JE, Hamblin L, Russell J, et al. Preventing Patient-toWorker violence in hospitals: outcome of a randomized controlled intervention. J Occup Environ Med 2017;59:18-27.

8. Moher D, Liberati A, Tetzlaff J, et al. Preferred reporting items for systematic reviews and meta-analyses: the PRISMA statement. PLOS Med 2009;6:e1000097.

9. Higgins JPT, Green S. Cochrane Handbook for Systematic Reviews of Interventions Version 5.1.0 [updated March 2011]. The Cochrane Collaboration, 2011.

10. Howick J, Chalmers I, OCEBM Levels of Evidence Working Group. The Oxford 2011 levels of evidence 2, 2011. Available: http://www. cebm.net/index.aspx?o=1025

11. Guyatt GH, Oxman AD, Kunz R, et al. What is 'quality of evidence' and why is it important to clinicians? BMJ 2008;336:995-8.

12. Guyatt GH, Oxman AD, Vist GE, et al. Grade: an emerging consensus on rating quality of evidence and strength of recommendations. $B M J$ 2008;336:924-6.

13. Lewin S, Booth A, Glenton C, et al. Applying GRADE-CERQual to qualitative evidence synthesis findings: introduction to the series. Implementation Sci 2018;13(Suppl 1).

14. Lipscomb J, McPhaul K, Rosen J, et al. Violence prevention in the mental health setting: the new York state experience. Can J Nurs Res 2006;38:96-117.

15. Mohr DC, Warren N, Hodgson MJ, et al. Assault rates and implementation of a workplace violence prevention program in the Veterans health care administration. J Occup Environ Med 2011;53:511-6. 
16. Magnavita N, Heponiemi T. Violence towards health care workers in a public health care facility in Italy: a repeated cross-sectional study. BMC Health Serv Res 2012;12.

17. Henson B. Preventing interpersonal violence in emergency departments: practical applications of criminology theory. Violence Vict 2010;25:553-65.

18. Magin P, Adams J, Joy E, et al. Violence in general practice: perceptions of cause and implications for safety. Can Fam Physician 2008;54:1278-84.

19. Wright NMJ, Dixon CAJ, Tompkins CNE. Managing violence in primary care: an evidence-based approach. Br J Gen Pract 2003;53:557-62.

20. Phillips JP. Workplace violence against health care workers in the United States. N Engl J Med Overseas Ed 2016;374:1661-9.

21. Gillespie GL, Gates DM, Miller M, et al. Workplace violence in healthcare settings: risk factors and protective strategies. Rehabil Nurs 2010;35:177-84

22. Sim MG, Wain T, Khong E. Aggressive behaviour - prevention and management in the general practice environment. Aust Fam Physician 2011;40:866-72.

23. Ifediora $\mathrm{C}$. Exploring the safety measures by doctors on after-hours house call services. Australas Med J 2015;8:239-46.

24. Morken T, Johansen IH. Safety measures to prevent workplace violence in emergency primary care centres-a cross-sectional study. BMC Health Serv Res 2013;13:384.

25. Price $\mathrm{O}$, Baker J, Bee $\mathrm{P}$, et al. Learning and performance outcomes of mental health staff training in de-escalation techniques for the management of violence and aggression. $\mathrm{Br} J$ Psychiatry 2015;206:447-55.

26. Price O, Baker J. Key components of de-escalation techniques: a thematic synthesis. Int J Ment Health Nurs 2012;21:310-9.

27. Saragoza P, White SG. Workplace violence: practical considerations for mental health professionals in consultation, assessment, and management of risk. Psychiatr Clin North Am 2016;39:599-610.

28. Abderhalden C, Needham I, Dassen T, et al. Structured risk assessment and violence in acute psychiatric wards: randomised controlled trial. Br J Psychiatry 2008;193:44-50.

29. Runyan CW, Zakocs RC, Zwerling C. Administrative and behavioral interventions for workplace violence prevention. Am J Prev Med 2000;18(Suppl 4):116-27.

30. Garriga M, Pacchiarotti I, Kasper S, et al. Assessment and management of agitation in psychiatry: expert consensus. World $J$ Biol Psychiatry 2016;17:86-128.

31. Richmond JS, Berlin JS, Fishkind AB, et al. Verbal De-escalation of the agitated patient: consensus statement of the American association for emergency psychiatry project beta De-escalation Workgroup. West J Emerg Med 2012;13:17-25.

32. Kohlrieser G. Hostage at the table: how leaders can overcome conflict, influence others, and raise performance. Jossy-Bass, 2006.

33. Geoffrion S, Lanctôt N, Marchand A, et al. Predictors of trivialization of workplace violence among healthcare workers and law enforcers. $J$ Threat Assess Manag 2015;2:195-213.

34. Naish J, Carter YH, Gray RW, et al. Brief encounters of aggression and violence in primary care: a team approach to coping strategies. Fam Pract 2002;19:504-10.

35. Schat $\mathrm{ACH}$, Kelloway EK. Reducing the adverse consequences of workplace aggression and violence: the buffering effects of organizational support. J Occup Health Psychol 2003;8:110-22.

36. Magnavita N. Violence prevention in a small-scale psychiatric unit: program planning and evaluation. Int $J$ Occup Environ Health 2011;17:336-44.

37. Robson LS, Clarke JA, Cullen K, et al. The effectiveness of occupational health and safety management system interventions: a systematic review. Saf Sci 2007;45:329-53.

38. James S, Cawood C. Violence assessment and intervention. In: The practitioner's handbook. 2nd edn, 2009: 377.

39. Joa TS, Morken T. Violence towards personnel in out-of-hours primary care: a cross-sectional study. Scand J Prim Health Care 2012;30:55-60.

40. Arnetz JE, Hamblin L, Ager J, et al. Application and implementation of the hazard risk matrix to identify Hospital workplaces at risk for violence. Am J Ind Med 2014;57:1276-84.

41. Runyan CW. Moving forward with research on the prevention of violence against workers. Am J Prev Med 2001;20:169-72.

42. Arnetz JE, Arnetz BB. Implementation and evaluation of a practical intervention programme for dealing with violence towards health care workers. J Adv Nurs 2000;31:668-80.

43. Rogers $P$, Miller G, Paterson B, et al. Is breakaway training effective? examining the evidence and the reality. J MH Training, Ed and Practice 2007;2:5-12.
44. Hvidhjelm J, Sestoft D, Skovgaard LT, et al. Sensitivity and specificity of the Brøset violence checklist as predictor of violence in forensic psychiatry. Nord J Psychiatry 2014;68:536-42.

45. Partridge B, Affleck J. Predicting aggressive patient behaviour in a hospital emergency department: an empirical study of security officers using the Brøset violence checklist. Australas Emerg Care 2018;21:31-5.

46. Nau J, Dassen T, Needham I, et al. The development and testing of a training course in aggression for nursing students: a pre-and posttest study. Nurse Educ Today 2009;29:196-207.

47. Hills DJ, Joyce CM, Humphreys JS. Workplace aggression prevention and minimisation in Australian clinical medical practice settings - a national study. Aust. Health Review 2013;37:607-13.

48. Gillespie GL, Gates DM, Mentzel T, et al. Evaluation of a comprehensive ED violence prevention program. J Emerg Nurs 2013;39:376-83.

49. Holloman GH, Zeller SL. Overview of project beta: best practices in evaluation and treatment of agitation. West $J$ Emerg Med 2012;13:1-2

50. Stowell KR, Florence P, Harman HJ, et al. Psychiatric evaluation of the agitated patient: consensus statement of the American association for emergency psychiatry project beta psychiatric evaluation Workgroup. West J Emerg Med 2012;13:11-16.

51. Wilson MP, Pepper D, Currier GW, et al. The psychopharmacology of agitation: consensus statement of the American association for emergency psychiatry project beta psychopharmacology Workgroup. West J Emerg Med 2012;13:26-34

52. Morken T, Johansen IH, Alsaker K. Dealing with workplace violence in emergency primary health care: a focus group study. BMC Fam Pract 2015;16:51.

53. Magin P. General practice as a fortress. Aust Fam Physician 2010;39.

54. Magin P, Adams J, Joy E. Occupational violence in general practice. Aust Fam Physician 2007;36:955-7.

55. The Royal Australian College of General Practitioners. General practice - a safe place. A guide for the prevention and management of patient-initiated violence, 2015. http://www.racgp.org.au/download/ documents/PracticeSupport/2011asafeplace-tipsandtools.pdf

56. Wax JR, Pinette MG, Cartin A. Workplace Violence in Health Care-lt's Not "Part of the Job". Obstet Gynecol Surv 2016;71:427-34.

57. Occupational Safety and Health Administration. Guidelines for preventing workplace violence for healthcare and social service workers, 2016. Available: https://www.osha.gov/Publications/osha3148.pdf

58. Calow N, Lewis A, Showen S, et al. Literature synthesis: patient aggression risk assessment tools in the emergency department. $J$ Emerg Nurs 2016;42:19-24.

59. Kynoch K, Wu C-J, Chang AM. Interventions for preventing and managing aggressive patients admitted to an acute hospital setting: a systematic review. Worldviews Evid Based Nurs 2011;8:76-86.

60. Lipscomb JA, El Ghaziri M. Workplace violence prevention: improving front-line health-care worker and patient safety. New Solut 2013;23:297-313.

61. Wassell JT. Workplace violence intervention effectiveness: a systematic literature review. Saf Sci 2009;47:1049-55.

62. Morphet J, Griffiths D, Beattie J, et al. Prevention and management of occupational violence and aggression in healthcare: a scoping review. Collegian 2018;25:621-32.

63. Wiskow C. Guidelines on workplace violence in the health sector, comparison of major known national guidelines and strategies, 2003.

64. WorkSafe Victoria. Prevention and management of violence and aggression in health services 2017

65. NICE. Violence and aggression, short-term management in mental health, health and community settings: updated edition, 2015. Available: http://www.ncbi.nlm.nih.gov/pubmed/26180871

66. FOD Binnenlandse Zaken, FOD Volksgezondheid. Veiligheid voor huisartsen, 2009

67. IBZ. Een veilige dokterspraktijk, 2017. Available: https://www.besafe. be/publicaties/een-veilige-dokterspraktijk

68. Aydin B, Kartal M, Midik O, et al. Violence against general practitioners in turkey. J Interpers Violence 2009;24:1980-95.

69. Zhao S, Qu L, Liu H, et al. Coping with workplace violence against general practitioners and nurses in Heilongjiang Province, China: social supports and prevention strategies. PLoS One 2016;11:e0157897-14.

70. Daffern M, Day A, Cookson A. Implications for the prevention of aggressive behavior within psychiatric hospitals drawn from interpersonal communication theory. Int $J$ Offender Ther Comp Criminol 2012;56:401-19.

71. Landau SF, Bendalak J, Amitay G, et al. Factors related to negative feelings experienced by emergency department patients and accompanying persons: an Israeli study. Isr J Health Policy Res 2018;7:1-9. 